\title{
Chromogranin A in Children with Neuroblastoma Serum Concentration Parallels Disease Stage and Predicts Survival
}

Ray J. Hsiao, * Robert C. Seeger,"5 Alice L. Yu," and Daniel T. O’Connor* Departments of ${ }^{*}$ Medicine and "Pediatrics, University of California, and Veterans Administration Medical Center, San Diego, California 92161; 'Division of Hematology/Oncology, Department of Pediatrics, Children's Hospital of Los Angeles and University of Southern California School of Medicine, Los Angeles, California 90054; and ${ }^{\S}$ Children's Cancer Study Group, Pasadena, California 91109

\begin{abstract}
Chromogranin $\mathbf{A}$ is an acidic protein costored and coreleased with catecholamines from storage vesicles. Its serum concentration is elevated in patients with peptide-producing endocrine neoplasia. We measured serum chromogranin $A$ at the time of diagnosis in 34 children with all stages of neuroblastoma. With a sensitivity of $91 \%$ and specificity of $100 \%$, serum chromogranin A emerged as a useful diagnostic tool for neuroblastoma, comparable to or better than other measurements such as neuron-specific enolase, ferritin, or dopamine-beta-hydroxylase. Mean serum chromogranin A correlated with disease stage $(r=0.76, P<0.01)$. The relationship of prognosis (progression-free survival) to baseline serum chromogranin $A$, age, and disease stage was determined in 34 patients at risk for relapse, with a median followup period of 18 mo (range, 1-48 mo). The survival rate for patients with lower serum chromogranin A levels ( $<190 \mathrm{ng} / \mathrm{ml}$ at the time of diagnosis) was $69 \%$, whereas it was $30 \%$ for those with higher chromogranin A levels $(P<0.05)$. Furthermore, when subjects were additionally stratified by either age or stage, chromogranin $A$ was an effective prognostic tool in patients who either were older than 1 yr $(P<0.005)$ or had more advanced disease (stage III or IV; $P<0.05)$. We conclude that serum chromogranin $A$ in neuroblastoma is (a) a valuable (sensitive and specific) diagnostic tool, (b) a correlate of tumor burden, and (c) a useful predictor of survival. (J. Clin. Invest. 1990. 85:1555-1559.) chromogranin • neuroblastoma
\end{abstract}

\section{Introduction}

Chromogranin A $(1,2)$, an acidic monomeric protein (3), is costored and coreleased with catecholamines by exocytosis from catecholamine storage vesicles $(4,5)$. Plasma chromogranin A is elevated in patients with peptide-producing endocrine neoplasia, such as pheochromocytoma, parathyroid adenoma, thyroidal $\mathrm{C}$ cell disorder, carcinoid tumor, oat cell lung carcinoma, and pancreatic islet cell tumor (6).

Neuroblastoma, the most common extracranial solid tumor of childhood, nearly always has characteristics of adrenergic neuroblasts. It can either spontaneously regress or respond poorly to therapeutic intervention. Several prognostic factors, such as extent of disease (stage) (7-9), age (7-9), serum

Address reprint requests to Dr. D. T. O'Connor, Nephrology/Hypertension (V-111-H), VA Medical Center, San Diego, CA 92161.

Received for publication 20 June 1989 and in revised form $20 \mathrm{Oc}$ tober 1989.

The Journal of Clinical Investigation, Inc.

Volume 85, May 1990, 1555-1559 neuron-specific enolase $(10,11)$, serum ferritin $(12,13)$, tumor histopathology (14), and tumor N-myc gene copy number (15), have been used to predict progression-free survival (16). In this study, we evaluated serum chromogranin A concentration as a diagnostic and prognostic tool for neuroblastoma.

\section{Methods}

\section{Human subject samples}

To assess the sensitivity and specificity of chromogranin $A$ as a diagnostic tool in evaluating neuroblastoma, we obtained serum samples from children without neuroblastoma $(n=38$; among them, 23 children were normal, and 15 children had nonpeptide-producing neoplasms, such as skeletal neoplasms, hepatoblastoma, leukemia, retinoblastoma, rhabdomyosarcoma, and ependymoma) and from affected children (at the time of diagnosis) with all stages of neuroblastoma ( $n$ $=34 ; 4$ stage I, 5 stage II, 10 stage III, 10 stage IV, and 5 stage IV-S). The 34 subjects were not consecutive, but were instead selected to represent all stages of neuroblastoma. All neuroblastoma subjects had the following data for analysis: age at diagnosis, sex, stage of disease using criteria of Evans et al. (7), and followup information for evaluation of progression-free survival. Stages I, II, or IV-S neuroblastoma patients were treated with conventional therapy at the discretion of their physicians, whereas stage III or IV neuroblastoma patients were treated according to Children's Cancer Study Group protocols, as previously described (15).

Neuroblastoma tumor. Human neuroblastoma tumor tissue, stored frozen after excision, was minced and homogenized at $0^{\circ} \mathrm{C}$ with an Ultraturrax (Tekmar Co., Cincinnati, $\mathrm{OH}$ ), at 20\% tissue/buffer weight per volume ratio in $0.1 \mathrm{mM}$ phenylmethyl-sulfonyl fluoride, $0.1 \mathrm{mM}$ ethylenediamine tetraacetic acid, $0.1 \mathrm{mM}$-ethyl maleiimide, and 10 $\mathrm{mM}$ ammonium acetate, $\mathrm{pH}$ 6.5. The homogenates were frozen and thawed to lyse any storage granules, and then centrifuged at $10,000 \mathrm{~g}$ for $10 \mathrm{~min}$ to sediment cell debris. The supernatants were frozen at $-70^{\circ} \mathrm{C}$ for chromogranin $\mathrm{A}$ radioimmunoassay.

Homogenates were also obtained from human sympathetic axons (autopsy vas deferens, $n=4$ ).

Chromogranin A radioimmunoassay. Human chromogranin A was isolated and characterized from chromaffin granules of human pheochromocytomas, as previously described $(3,6,17)$. Human chromogranin A was measured by a rapid modification (18) of the double antibody radioimmunoassay previously described (19).

Serum samples were coded and the clinical data were unknown to personnel performing the assays. Serum values of $>52 \mathrm{ng} / \mathrm{ml}$ were considered abnormal.

Dopamine-beta-hydroxylase measurement. Serum dopaminebeta-hydroxylase was measured spectrophotometrically as previously described $(20,21)$. Serum dopamine-beta-hydroxylase values for pediatric normal controls $(n=19$, from 2 mo to 11 -yr old) were $3 \pm 1$ IU/liter, results consistent with previous reports $(22,23)$. Serum values of $>5 \mathrm{IU} /$ liter were considered abnormal.

\section{Statistics}

Results are reported as mean \pm SEM, unless otherwise stated. Descriptive statistics (mean and SE) and inferential statistics (linear regression, 
$t$ tests and one-way analysis of variance) were generated by statistics software packages (Cricket Graph and Statworks; Cricket Software, Philadelphia, PA) on a Macintosh microcomputer.

Progression-free survival was estimated from the date of diagnosis to the date of last follow-up, or until disease progression was noted or death occurred. Estimates of progression-free survival of various subgroups of children with neuroblastoma were calculated using the method of Kaplan and Meier (24). A log-rank test (life-table analysis) was used for the comparison of survival between groups of patients (25, 26). Comparisons of chromogranin A levels between stages were analyzed using a one-way analysis of variance. Analysis of neuroblastoma patients' survival pivoted about a serum chromogranin A value of 190 $\mathrm{ng} / \mathrm{ml}$, since preliminary inspection of the data indicated that this value best differentiated progression-free survivors from those with progression of disease or death.

\section{Results}

Table I displays serum chromogranin A, dopamine-beta-hydroxylase, and age in control subjects $(n=38)$ or patients with various stages of neuroblastoma $(n=34)$. Chromogranin A did not vary with age. Normal adults (age range: $19-75 \mathrm{yr}$ ) had a mean chromogranin A of $28 \pm 1 \mathrm{ng} / \mathrm{ml}$ (range: $19-52 \mathrm{ng} / \mathrm{ml}$ ), whereas normal children (age range: 1 mo to $18 \mathrm{yr}$ ) had a mean

Table I. Plasma Chromogranin A in Neuroblastoma Patients Stratified by Disease Stage

\begin{tabular}{|c|c|c|c|c|}
\hline Status & $n$ & Age (range) & $\mathrm{CgA}$ & DBH \\
\hline & & $y r$ & $n g / m l$ & IU/liter \\
\hline Normal controls & 23 & $\begin{array}{l}6.7 \pm 0.1^{*} \\
(0.4-14)\end{array}$ & $28 \pm 2$ & $\begin{array}{c}3 \pm 1 \\
(n=19)^{4}\end{array}$ \\
\hline Other tumors & 15 & $\begin{array}{r}10.9 \pm 1.6 \\
(0.1-18)\end{array}$ & $25 \pm 3$ & $\|$ \\
\hline Stage I & 4 & $\begin{array}{l}1.3 \pm 0.6 \\
(0.3-2)\end{array}$ & $68 \pm 10$ & $20 \pm 11$ \\
\hline Stage II & 5 & $\begin{array}{r}6.0 \pm 3.1 \\
(0.2-18)\end{array}$ & $77 \pm 14$ & $20 \pm 6$ \\
\hline Stage III & 10 & $\begin{array}{r}3.7 \pm 1.5 \\
(0.7-16)\end{array}$ & $234 \pm 91$ & $15 \pm 3$ \\
\hline Stage IV & 10 & $\begin{array}{l}2.8 \pm 0.5 \\
(0.3-6)\end{array}$ & $1246 \pm 539$ & $24 \pm 14$ \\
\hline Stage IV-S & 5 & $\begin{array}{c}0.4 \pm 0.1 \\
(0.1-0.8)\end{array}$ & $1661 \pm 842$ & $12 \pm 2$ \\
\hline All stages & 34 & $\begin{array}{r}3.0 \pm 0.7 \\
(0.1-18)\end{array}$ & $699 \pm 220$ & $19 \pm 5$ \\
\hline
\end{tabular}

$\mathrm{CgA}$, chromogranin A (pediatric normal $<52 \mathrm{ng} / \mathrm{ml}$ ); DBH, dopamine-beta-hydroxylase (pediatric normal $\leq 5 \mathrm{IU} /$ liter, defined as mean \pm 2 SD).

* Plus-minus values are mean \pm SEM.

‡ Only $n$ samples were assayed. The mean age was $2.6 \pm 0.7 \mathrm{yr}$ (range, $0.2-11 \mathrm{yr}$ ).

\$ Other neoplasms: osteosarcoma $(n=4)$, Ewing's sarcoma $(n=2)$, adamantinoma of long bone $(n=1)$, hepatoblastoma $(n=1)$, leukemia $(n=3)$, retinoblastoma $(n=1)$, rhabdomyosarcoma $(n=2)$, and ependymoma $(n=1)$.

"Samples were not assayed. level of $28 \pm 2 \mathrm{ng} / \mathrm{ml}$. In the pediatric group, there was no correlation of serum chromogranin A with age $(r=0.13, n=23, P$ $>0.1$ ). Normal serum chromogranin A levels were found in subjects with tumors other than neuroblastoma ( $n=15$, mean: $25 \pm 3 \mathrm{ng} / \mathrm{ml}$, range: $11-52 \mathrm{ng} / \mathrm{ml}$ ), whereas elevated levels were found in children with all stages of neuroblastoma (Table I).

Table II compares the sensitivities and specificities of serum chromogranin A and dopamine-beta-hydroxylase for detection of neuroblastoma. Elevated serum chromogranin A had a sensitivity of $91 \%(31 / 34)$ and a specificity of $100 \%$ $(38 / 38)$ for neuroblastoma, suggesting that it may be a useful diagnostic tool. Elevated dopamine-beta-hydroxylase was also sensitive $(85 \%)$ and specific $(100 \%)$.

${ }^{125}$ I-labeled chromogranin A was displaced from antihuman chromogranin A antibody in parallel by neuroblastoma tumor chromogranin A and the chromogranin A standard, indicating authentic chromogranin $\mathrm{A}$ immunoreactivity in a neuroblastoma. This tumor had a chromogranin A concentration of $2,142 \mathrm{ng} / \mathrm{g}$ wt. Human sympathetic nerve homogenates contained a similar amount of chromogranin A immunoreactivity $(2,827 \pm 772 \mathrm{ng} / \mathrm{g})$.

Serum chromogranin A correlated with neuroblastoma stage $(r=0.72, n=67$, including 29 stages I-IV patients, plus 38 controls, $P<0.01$, Fig. 1). The correlation of disease stage with serum chromogranin A was superior to the corresponding correlations with serum dopamine-beta-hydroxylase $(r=0.53$, $n=48$ including controls, $P<0.01$ ), inasmuch as dopaminebeta-hydroxylase did not change appreciably with stage (Table I).

Next, we evaluated the prognostic importance of serum chromogranin A in neuroblastoma patients. Fig. 2 illustrates estimated progression-free survival stratified by serum chromogranin A level alone. Affected children with serum chromogranin $A<190 \mathrm{ng} / \mathrm{ml}$ had an estimated progression-free survival rate of $69 \%$, vs. $30 \%$ in children with higher serum chromogranin A levels $(P<0.005)$.

When the group was further stratified by both age and serum chromogranin A level, chromogranin A was a significant predictor of progression-free survival especially in older children with neuroblastoma. In children who were older than 1 yr of age (at diagnosis), those who had higher serum chromogranin A ( $\geq 190 \mathrm{ng} / \mathrm{ml})$ had a worse prognosis than those with lower levels $(P<0.005$, Fig. 3$)$. In children who were younger than 1 yr of age (at time of diagnosis), those who had higher serum chromogranin $A(\geq 190 \mathrm{ng} / \mathrm{ml})$ also had a worse prognosis than those with lower levels (67 vs. $100 \%)$. The dif-

Table II. Sensitivity and Specificity of Plasma Chromogranin A for Diagnosis of Neuroblastoma

\begin{tabular}{crr}
\hline Test & CgA & \multicolumn{1}{c}{ DBH } \\
\hline Sensitivity* & $91 \%(31 / 34)$ & $85 \%(29 / 34)$ \\
Specificity $^{\ddagger}$ & $100 \%(38 / 38)$ & $100 \%(19 / 19)$ \\
\hline
\end{tabular}

CgA, Chromogranin A (pediatric normal $<52 \mathrm{ng} / \mathrm{ml}$ ); DBH, dopamine-beta-hydroxylase (pediatric normal $\leq 5$ IU/liter).

* Sensitivity, (true-positive)/(true-positive + false-negative).

‡ Specificity, (true-negative)/(true-negative + false-positive). True negative and false positives were normal pediatric controls or children with nonneuroblastoma neoplasms. 


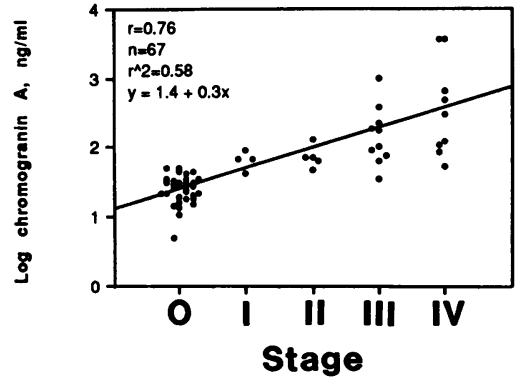

Figure 1. Serum chromogranin A at time of diagnosis in neuroblastoma patients $(n=29)$ stratified by disease stage. Neuroblastoma patients were staged using criteria of Evans et al. (7). Pediatric controls $(n=38 ; 23$ normal controls and 15 patients with other, nonneuroendocrine tumors; see Table I) are denoted by stage 0 . Stage IV-S patients $(n=5)$ are not included in this figure. $\log _{10}$ of serum chromogranin A correlates with disease stage $(P$ $<0.01$ ). There is a stepwise increase in serum chromogranin A with extent of disease.

ference did not, however, reach statistical significance $(P$ $>0.1$ ).

Progression-free survival rate was also evaluated in subjects stratified by both stage and serum chromogranin A level (Fig. 4). In patients with more advanced disease at the time of diagnosis, those who had higher serum chromogranin A $(\geq 190$ $\mathrm{ng} / \mathrm{ml}$ ) also had a worse prognosis than those with lower levels $(P<0.05$, Fig. 4).

Dopamine-beta-hydroxylase was not of prognostic value, since its mean serum concentration was similar in disease stages I-IV (Table I).

\section{Discussion}

Neuroblastoma is characterized by high variability in response to therapeutic intervention. Most patients with local or regional disease are successfully treated with surgery alone or surgery combined with chemotherapy and radiation. However, conventional treatment for nearly all patients with advanced neuroblastoma has generally been ineffective. Re-

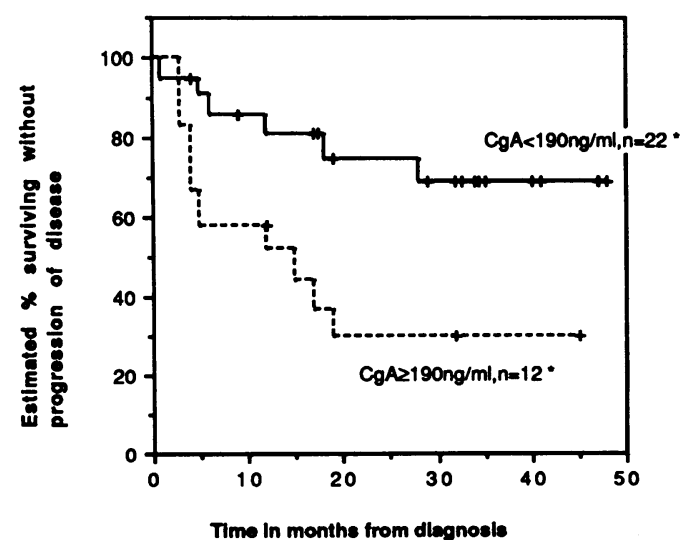

Figure 2. Estimated progression-free survival for patients with neuroblastoma as a function of serum chromogranin $\mathrm{A}(\mathrm{CgA})$ concentration at diagnosis. Progression-free survival was $69 \%$ if chromogranin A was below $190 \mathrm{ng} / \mathrm{ml}$ and 30\% if chromogranin A was above 190 $\mathrm{ng} / \mathrm{ml}$. The statistically significant difference is noted by ${ }^{*}, P<0.005$ at $48 \mathrm{mo}$. The median follow-up of progression-free survivors was 18 mo, and the range was 1-48 mo. + marks on each curve represent the last followups for individuals who are progression-free.

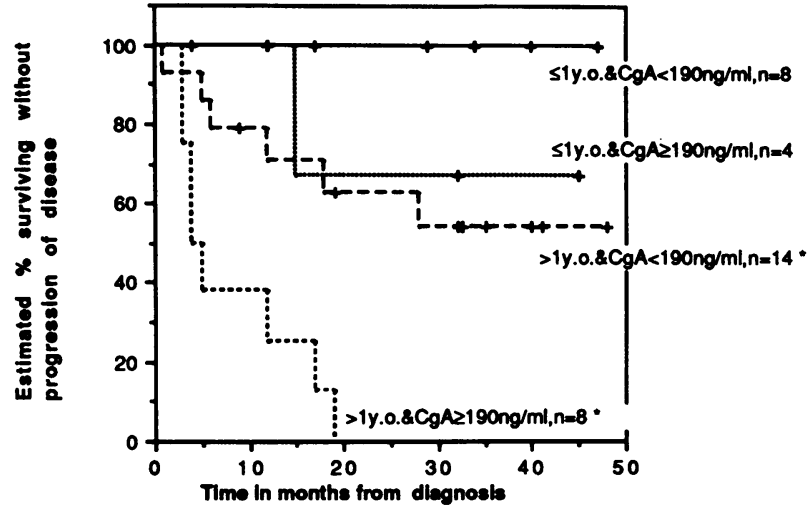

Figure 3. Estimated progression-free survival for patients with neuroblastoma stratified by both age and serum chromogranin $\mathrm{A}(\mathrm{CgA})$ level $(\gtrless 190 \mathrm{ng} / \mathrm{ml})$ at time of diagnosis. In children who are $>1-\mathrm{yr}$ old (y.o.) at diagnosis, those with lower chromogranin A levels have a better prognosis than those with higher levels ( $54 \mathrm{vs.} 0 \%$ progression-free survival at $\mathbf{4 8} \mathrm{mo}$; the statistically significant difference is noted by ${ }^{*}, P<0.005$ ). + marks on each curve represent the last followup for individuals who are progression-free survivors.

cently, patients with widespread disease have been successfully treated using massive chemotherapy with or without totalbody irradiation followed by bone marrow transplant (27-29). Because such aggressive treatment is not warranted in all neuroblastoma patients, reliable prognostic tests are needed. Previously described guides to prognosis include age at diagnosis (7-9), disease stage (7-9), tumor N-myc oncogene copy number (15), serum neuron-specific enolase $(10,11)$, serum ferritin $(12,13)$, and tumor histopathology (14).

Our study demonstrates that serum chromogranin $A$ is increased in nearly all patients with neuroblastoma, and that the level of elevation is higher in regional or metastatic than in localized disease. Compared to other neuroblastoma markers (i.e., ferritin $(12,13)$, neuron-specific enolase $(10,11)$, and

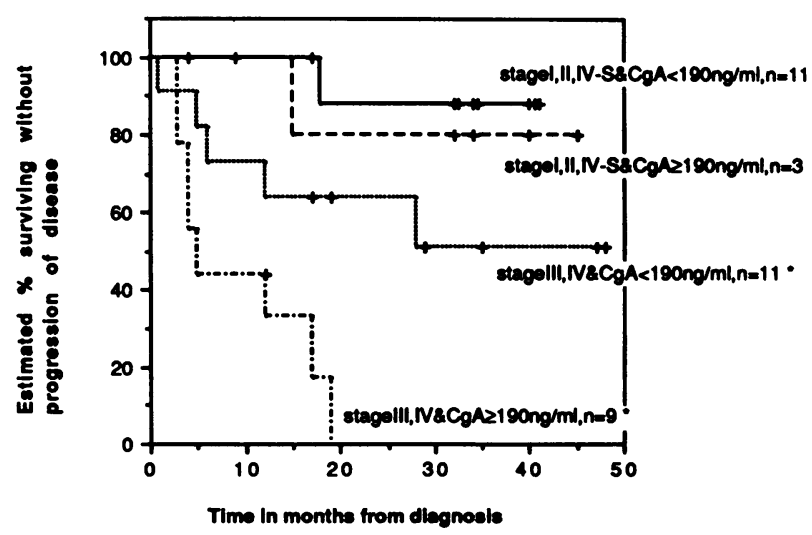

Figure 4. Estimated progression-free survival for patients with neuroblastoma stratified by stage and serum chromogranin $\mathrm{A}(\mathrm{CgA})$ $(\gtrless 190 \mathrm{ng} / \mathrm{ml}$ ) at time of diagnosis. Serum chromogranin $A$ is a significant prognostic factor in patients with regional or metastatic (stages III or IV) disease (the statistically significant difference of the estimated progression-free survival is noted by $*, P<0.05)$. + marks on each curve represent the last followups for individuals who are progression-free survivors. 
dopamine-beta-hydroxylase), chromogranin A had a higher sensitivity for the detection of neuroblastoma. Because chromogranin A concentration in a neuroblastoma homogenate was $2,142 \mathrm{ng} / \mathrm{g}$, the tumor cells are the likely source of the elevated chromogranin A in neuroblastoma patients' sera. Furthermore, there was a strong correlation between extent of disease and serum chromogranin A (Fig. 1). Patients with advanced disease stages (stages III, IV, or IV-S) have higher serum levels than those with localized disease (stages I or II) (Fig. 1), which suggests that serum chromogranin A is a correlate of tumor burden.

Unlike ferritin $(12,13)$, neuron-specific enolase $(10,11)$, and dopamine-beta-hydroxylase, serum chromogranin A was at least as high in stage IV-S as in stage IV (Table I), even though overall tumor burden is characteristically less in stage IV-S than in stage IV (7-9). Perhaps chromogranin A expression is also a function of degree of neuroendocrine differentiation of neuroblastoma tissue $(30,31)$.

Serum chromogranin A was a significant prognostic factor when considered alone or when combined with either stage or age. In children older than $1 \mathrm{yr}$ at the time of diagnosis, lower serum chromogranin $\mathrm{A}(<190 \mathrm{ng} / \mathrm{ml})$ was associated with a better prognosis than higher serum chromogranin A ( $P$ $<0.005,54$ vs. $0 \%$, Fig. 3 ). It should be noted that, regardless of chromogranin A, children $<1$-yr old at the time of neuroblastoma diagnosis had a comparatively good prognosis (Fig. 3). In patients with more advanced disease (stages III \& IV), those who had lower serum chromogranin A $(<190 \mathrm{ng} / \mathrm{ml})$ also had a better prognosis than others with higher levels $(P$ $<0.05,51$ vs. $0 \%$, Fig. 4 ).

In conclusion, measurement of serum chromogranin A can provide a novel and useful test for the evaluation of both suspected and definite neuroblastoma. Its high specificity and sensitivity suggest value in differential diagnosis. As a prognostic test, it appears to have merit for guiding therapeutic decisions. Further studies, such as evaluation of the relationship of serum chromogranin A to neuroblastoma progression or remission, might expand the clinical use of this measurement.

\section{Acknowledgments}

We thank Ms. Annie Chen and Ms. Sylvia Rayner for their excellent technical assistance, and Drs. Henry F. Krous, Glenn F. Billman, and John Bastian as well as Mr. Ron Ogdon for normal control sera.

Supported by the Veterans Administration, the National Institutes of Health (HL-35018, CA-02649, and CA-22794), and the American Heart Association.

\section{References}

1. Smith, A. D., and H. Winkler. 1967. Purification and properties of an acidic protein from chromaffin granules of bovine adrenal medulla. Biochem. J. 103:483-492.

2. Smith, W. J., and N. Kirshner. 1967. A specific soluble protein from the catecholamine storage vesicles of bovine adrenal medulla. I. Purification and chemical characterization. Mol. Pharmacol. 3:52-62.

3. O'Connor, D. T., R. P. Frigon, and R. L. Sokoloff. 1984. Human chromogranin A: purification and characterization from catecholamine storage vesicles of human pheochromocytoma. Hypertension (Dallas). 6:2-12.
4. Blaschko, H., R. S. Comline, F. J. Schneider, M. Silver, and A. D. Smith. 1967. Secretion of a chromaffin granule protein, chromogranin, from the adrenal gland after splanchnic stimulation. Nature (Lond.). 215:58-59.

5. Sage, J. H., W. J. Smith, and N. Kirshner. 1967. Mechanism of secretion from the adrenal medulla. I. A microquantitative immunologic assay for bovine adrenal catecholamine storage vesicle protein and its application to studies of the secretory process. Mol. Pharmacol. 3:81-89.

6. O'Connor, D. T., and L. J. Deftos. 1986. Secretion of chromogranin A by peptide-producing endocrine neoplasms. N. Engl. J. Med. 314:1145-1151.

7. Evans, A. E., G. J. D'Angio, and J. Randolph. 1971. A proposed staging for children with neuroblastoma: children's cancer study group A. Cancer (Phila.). 27:374-378.

8. Evans, A. E. 1980. Natural history of neuroblastoma. In Advances in Neuroblastoma Research. A. E. Evans, editor. Raven Press, Ltd., New York. 3-12.

9. D'Angio, G. J., A. E. Evans, and C. E. Koop. 1971. Special pattern of widespread neuroblastoma with a favorable prognosis. Lancet. i:1046-1049.

10. Zeltzer, P. M., P. J. Marangos, and A. M. Parma. 1983. Elevated serum neuron-specific enolase in serum of children with metastatic neuroblastoma. Lancet. ii:361-363.

11. Zeltzer, P. M., P. J. Marangos, and A. E. Evans. 1986. Serum neuron-specific enolase in children with neuroblastoma. Cancer (Phila.). 57:1230-1234.

12. Hann, H. L., H. M. Levy, and A. E. Evans. 1980. Serum ferritin as a guide to therapy in neuroblastoma. Cancer. Res. 40:1411-1413.

13. Hann, H. L., A. E. Evans, S. E. Siegel, K. Y. Wong, H. Sather, A. Dalton, D. Hammon, and R. C. Seeger. 1985. Prognostic importance of serum ferritin in patients with stage III and IV neuroblastoma: the children's cancer study group experience. Cancer. Res. 45:28432848.

14. Shimada, H., J. Chatten, W. A. Newton, N. Sachs, A. B. Hamoudi, T. Chiba, H. E. Marsden, and K. Misugi. 1984. Histopathologic prognostic factors in neuroblastic tumors: definition of subtypes of ganglioneuroblastoma and an age-linked classification of neuroblastomas. JNCI (J. Nat. Cancer Inst.). 73:405-416.

15. Seeger, R. C., G. M. Brodeur, H. Sather, A. Dalton, S. E. Siegel, K. Y. Wong, and D. Hammond. 1985. Association of multiple copies of the N-myc oncogene with rapid progression of neuroblastomas. $N$. Engl. J. Med. 313:1111-1116.

16. Evans, A. E., G. J. D'Angio, K. Propert, J. Anderson, and H. W. Hann. 1987. Prognostic factors in neuroblastoma. Cancer (Phila.). 59:1853-1859.

17. O'Connor, D. T. 1986. Radioimmunoassays of chromogranin. In Quantitative Analysis of Catecholamines and Related Compounds. A. M. Krstulovic, editor. John Wiley \& Sons Ltd., Chichester. 302-315.

18. O'Connor, D. T., and K. N. Bernstein. 1984. Radioimmunoassay of chromogranin A in plasma as a measure of exocytotic sympathoadrenal activity in normal subjects and patients with pheochromocytoma. N. Engl. J. Med. 311:764-770.

19. O'Connor, D. T., M. R. Pandian, E. Carlton, J. H. Cervenka, and R. J. Hsiao. 1989. Rapid measurement of circulating human chromogranin A: in vitro stability, exploration of the neuroendocrine character of neoplasia, and assessment of the effects of organ failure. Clin. Chem. 35:1631-1637.

20. Nagatsu, T., and S. Udenfriend. 1972. Photometric assay of dopamine-beta-hydroxylase activity in human blood. Clin. Chem. 18:980-983.

21. O'Connor, D. T., G. L. Levine, and R. P. Frigon. 1983. Homologous radio-immunoassay of human plasma dopamine-beta-hydroxylase: analysis of homospecific activity, circulating plasma pool and 
intergroup differences based on race, blood pressure and cardiac function. J. Hypertens. 1:227-233.

22. Goldstein, M., L. S. Freedman, A. C. Bohuon, and F. Guerinot. 1972. Serum dopamine-beta-hydroxylase activity in neuroblastoma. N. Engl. J. Med. 286:1123-1125.

23. Freedman, L. S., T. Ohuchi, M. Goldstein, F. Axelrod, I. Fish, and J. Dancis. 1972. Changes in human serum dopamine-beta-hydroxylase activity with age. Nature (Lond.). 236:310-311.

24. Kaplan, E., and P. Meier. 1958. Nonparametric estimation from incomplete observation. J. Am. Statist. Assoc. 53:457-481.

25. Peto, R., M. Pike, P. Armitage, M. E. Breslow, D. R. Cox, S. V. Howard, N. Mantel, K. McPherson, J. Peto, and P. G. Smith. 1977. Design and analysis of randomized clinical trials requiring prolonged observation of each patient. II. Analysis and examples. Br. J. Cancer. 35:1-39.

26. Matthews, D. E., and V. T. Farewell. 1988. Using and understanding medical statistics. Karger, Basel. 65-87.

27. August, C. S., F. T. Serota, P. A. Koch, E. Burkey, H. Schlesinger, W. L. Elkins, A. E. Evans, and G. J. D'Angio. 1984. Treatment of advanced neuroblastoma with supralethal chemotherapy, radiation and allogeneic or autologous marrow reconstruction. J. Clin. Oncol. 2:609-615.

28. Seeger, R. C., C. P. Reynolds, and T. J. Moss. 1987. Autologous bone marrow transplantation for poor-prognosis neuroblastoma. In Autologous Marrow Transplantation: Proceedings of the Third International Symposium. K. A. Dicke, G. Spitzer, and S. Jagannath, editors. MD Anderson Hospital and Tumor Institute at Houston, Houston. 375-382.

29. Philip, T., R. Ghalie, R. Pinkerton, J. M. Zucker, J. L. Bernard, G. Leverger, and O. Hartmann. 1987. A phase II study of high dose cisplatin and VP-16 in neuroblastoma: a report from the Societe Francaise d'Oncologie Pediatrique. J. Clin. Oncol. 5:941-950.

30. Helman, L. J., C. J. Thiele, W. M. Linehan, B. D. Nelkin, S. B. Baylin, and M. A. Israel. 1987. Molecular markers of neuroendocrine development and evidence of environmental regulation. Proc. Natl. Acad. Sci. USA. 84:2336-2339.

31. Cooper, M. J., L. J. Helman, A. E. Evans, S. Swamy, D. T. O'Connor, L. Helson, and M. A. Israel. 1988. Chromogranin A expression in childhood peripheral neuroectodermal tumors. Prog. Clin. Biol. Res. 271:175-184. 